\section{Kidney \\ Blood Pressure Research}

\title{
Dialysate Creatinine Response Patterns During Peritoneal Equilibration Test and the Association Between Cardiovascular Mortality: Findings from a Prospective Cohort Study
}

\author{
Dahai Yua,b Yamei Cai ${ }^{a}$ Rui Qina,c Xing Tian ${ }^{a} \quad$ Jing Xiao ${ }^{a}$ Zhanzheng Zhao \\ aDepartment of Nephrology, the First Affiliated Hospital, Zhengzhou University, Zhengzhou, China; \\ ${ }^{b}$ Arthritis Research UK Primary Care Centre, Research Institute for Primary Care \& Health Sciences, \\ Keele University, Keele, UK; ' cjiangsu Province Hospital on Integration of Chinese and Western Medicine, \\ Nanjing, China
}

\section{Key Words}

Peritoneal dialysis - Peritoneal equilibrium test $\cdot$ Dialysate creatinine $\cdot$ Latent class model $\bullet$ Cardiovascular mortality

\begin{abstract}
Background/Aims: During peritoneal equilibrium test (PET), intermediate measures of Dt/P (dialysate / plasma creatinine ratio), D0/P, D2/P and D4/P ratios might provide additional information regarding a patient's cardiovascular mortality. We aimed to characterise heterogeneity of dialysate creatinine response patterns based on three ratios and compare cardiovascular mortality risks by response patterns. Methods: 3,477 patients initialising peritoneal dialysis (PD) between 2007-2015 were measured D0/P, D2/P and D4/P at baseline and 2-year cardiovascular mortality was defined as the primary outcome. Latent class mixed-effect models were fitted to identify distinct patterns of dialysate creatinine response. Multivariable Logistic regression model with adjustment of cardiometabolic factors were used to compare cardiovascular mortality by latent classes. Results: The $1^{\text {st }}$ latent class including $36 \%$ of participants was characterised by consistently increasing and high Dt/P ratios both at 2 -hour and 4 -hour. The $2^{\text {nd }}$ class including $61 \%$ of participants characterised by sharply increased ratio at 2-hour and slightly increased ratio at 4-hour. The $3^{\text {rd }}$ class included $3 \%$ of participants with decreased ratio at 2-hour and increased ratio at 4-hour. Comparing the $1^{\text {st }}$ class, the lower cardiovascular mortality risk was identified in the $2^{\text {nd }}$ and $3^{\text {rd }}$ class with adjusted odds ratio 0.65 (95\% confidence interval: $0.62-0.69)$ and $0.48(0.41-0.57)$, respectively.
\end{abstract}

Dr. Zhanzheng Zhao

and Dr. Dahai Yu
Department of Nephrology, the First Affiliated Hospital of Zhengzhou University,

No.1 of East Jianshe Road, Zhengzhou 450052 (China)

Tel. +861393852 5666, E-Mail zhanzhengzhao@zzu.edu.cn, d.yu@keele.ac.uk 


\section{Kidney \\ Blood Pressure Research}

Kidney Blood Press Res 2018;43:162-169

\begin{tabular}{l|l}
\hline DOI: 10.1159/000487498 & (C) 2018 The Author(s). Published by S. Karger AG, Base
\end{tabular}

Published online: February 21, 2018 www.karger.com/kbr

Conclusion: Patients with decreased Dt/P ratio between 0-hour and 2-hour and low ratios at 2-hour and 4-hour tend to have low cardiovascular mortality. Latent class analysis seems to be a promising method to reveal unidentified subgroups that do not fit into the risk category defined by $\mathrm{Dt} / \mathrm{P}$ ratio at 4-hour.

(C) 2018 The Author(s)

Published by S. Karger AG, Basel

\section{Introduction}

Chronic kidney disease (CKD) has become a worldwide heath problem [1]. In particular, end-stage renal disease (ESRD) triggers premature mortality and a substantial health economic burden [2]. It has been estimated that more than $10.8 \%$ of Chinese adults (around 130 million) have CKD with dialysis needs at some point in their lives [3]. Increased coverage of Chinese medical insurance has made dialysis, especially peritoneal dialysis (PD), more affordable among Chinese patients with ESRD [4]. The leading cause of mortality among people accepting PD is cardiovascular disease (CVD) [5].

Patients treated with PD usually undergo a peritoneal equilibration test (PET) to characterize the rate of transfer of solute and water across the peritoneal barrier [6]. The test yields three parameters - 4-hour dialysate to plasma ratio of creatinine (D/P creatinine), 4to 0-hour dialysate glucose ratio (D/D0 glucose), and 4-hour ultrafiltration volume (UFV) [6]. Although the results of the PET can help optimize solute clearances, they are more often used to individualize PD prescriptions to maximize daily peritoneal ultrafiltration [7, 8]. Indeed, the higher risk for death or transfer to hemodialysis in individuals with faster solute transfer rate is thought to result from volume overload from challenges with fluid removal with continuous ambulatory PD in such patients [9]. Previous studies investigated the all-cause mortality and hospitalization risk using the three measurements at 4-hour [10]. It is unclear whether there is heterogeneity in measurement response curves during the PET is an alternative approach to identify a range of features that may reflect underlying pathophysiological mechanisms. Dialysate creatinine response reflecting the creatinine metabolism status associated with future risk of cardiovascular mortality has not been examined. Furthermore, investigating whether different dialysate creatinine response curves during the PET represent distinct cardiovascular risk profiles may contribute to elucidate the heterogeneity in the underlying pathophysiological pathways to cardiovascular mortality.

Now, we proposed latent class analyses to reveal heterogeneity in dialysate creatinine response patterns based on three time points (0-hour, 2-hour and 4-hour) during the PET, and thereafter compare the cardiovascular mortality rate between the identified latent classes. We hypothesise that there will be individuals at high risk not captured by classical one-time measures of risk.

\section{Materials and Methods}

\section{Data Setting}

The data used in this study was derived from the Henan Peritoneal Dialysis Registry (HPDR). Briefly, the HPDR is operated under the auspices of the Department of Nephrology, the First Affiliated Hospital of Zhengzhou University and provides an independent audit and analysis of renal care in Henan, China. During the study period, information was prospectively collected electronically from all renal units across Henan. Data arriving at the HPDR are subjected to an algorithm which identifies suspicious values, which are then further verified and corrected where necessary by contacting the renal unit.

\section{Study population}

This study was designed as a cohort study, which included all adults aged more than 18 years who commenced PD between 2007-2015 and who had at least two years' follow-up. Patients who died, underwent transplant or whose kidney function recovered within 90 days after initialisation of dialysis 


\section{Kidney Blood Pressure Research}

Yu et al.: Dialysate Creatinine Response Patterns and Cardiovascular Mortality

$(n=16)$ were excluded to avoid a reverse causality association between predictors and outcome. This reflects the standard approach to investigate "real" ESRD patients among all those receiving PD care.

\section{Outcomes}

The primary outcome of this study was defined as cardiovascular mortality. Cases were defined as deceased patients, on the HPDR, with CVD as the cause of death based on the diagnosis on death certificate.

\section{PET Test and dialysate creatinine measurements}

A standard PET was performed; dialysate samples were collected at times 0, 2-hour, and 4-hour, and a blood sample was collected at 120 minutes. All blood and dialysate samples were analysed within 24 hours. Three dialysate / plasma creatinine ratios: D0/P ratio (0-hour dialysate creatinine / plasma creatinine), D2/P ratio (2-hour dialysate creatinine / plasma creatinine) and D4/P ratio (4-hour dialysate creatinine / plasma creatinine) were used to quantify the dialysate creatinine response.

Ethics approval was granted by the Clinical Research Ethics Committee of the First Affiliated Hospital of Zhengzhou University. Written informed consent was obtained from all participants before inclusion.

\section{Covariables}

All available information, including comorbidities, demographic characteristics, and clinical measurements were collected at the time of patients initialising PD.

\section{Statistical Analysis}

We used latent class trajectory analysis to identify heterogeneous dialysate creatinine response patterns during the PET. Latent class growth analysis is a semi-parametric statistical technique that aims to model individual trajectories over time using polynomial curves after accounting for unobserved heterogeneity within the population $[11,12]$. A search for the optimum latent class growth model was conducted by fitting a one-class linear model to the data and then successively increasing the number of classes until model fit no longer improved. Model fit was based on statistical criteria (Bayesian information criterion (BIC)) and on a judgement of model interpretability [12]. In our study, the latent class mixed-effects model was specified with linear, quadratic and cubic time terms to model non-linear change over time [13-15]. Coefficients were allowed to vary between latent groups. After determining the best fitting model, each individual was assigned to the creatinine response pattern group (latent class) with the highest membership probability.

We then described the cardiometabolic characteristics (age, sex, smoking status, body mass index, lipid profile, phosphorus, estimated Glomerular Filtration rate and blood pressure) of study participants stratified by latent class.

Logistic regression models with adjustment for two sets of variables were used to compare risk of cardiovascular mortality between latent classes. Model 1 was adjusted for age and gender. Model 2 was additionally adjusted for other variables presented in Table 1.

Missing information was as follows: BMI (10.51\%), phosphate (10.23\%), albumin (9.92\%), total protein $(12.75 \%)$, total cholesterol (14.53\%), low density lipoprotein (14.58\%), high density lipoprotein (14.52\%), triglyceride (14.52\%), fasting glucose (15.26\%), SBP (2.26\%), and DBP (2.23\%). We used multiple imputation to replace missing values by using a chained equation approach based on all candidate predictors. We created 15 imputed datasets for missing variables that were then combined across all datasets by using Rubin's rule to obtain estimations.

All analyses were performed using STATA (STATA/SE 14.0 StataCorp, College Station, TX, USA). All P values were calculated using two-tailed tests and a $P$ value $<0.05$ was taken to indicate statistical significance.

\section{Results}

Three latent classes were identified, each including 36.1\%,61.2\%, and $2.7 \%$ of the study population (Fig. 1). Average posterior group membership probabilities were high, ranging between 0.85-0.96, indicating a good discrimination between the groups. 


\section{Kidney \\ Blood Pressure \\ Research}

Kidney Blood Press Res 2018;43:162-169

\begin{tabular}{l|l}
\hline DOI: 10.1159/000487498 & (C) 2018 The Author(s). Published by S. Karger AG, Base
\end{tabular}

Published online: February 21, 2018 www.karger.com/kb

Yu et al.: Dialysate Creatinine Response Patterns and Cardiovascular Mortality

Table 1. Cardiometabolic risk factor characteristics by latent class. Binary variables are displayed as numbers (percentage) and continuous variables are displayed as median (interquartile range). Variables were compared between latent groups using Kruskal-Wallis tests for continuous variables and $\chi 2$ tests for categorical variables. For all differences, p-values were $<0.001$

\begin{tabular}{|c|c|c|c|c|}
\hline Characteristics & Overall & Class 1 & Class 2 & Class 3 \\
\hline $\mathrm{N}$ & 3,477 & 1,255 & 2,127 & 95 \\
\hline Male Gender, n (\%) & $2,050(59.0)$ & $795(63.3)$ & $1,204(56.6)$ & $51(53.5)$ \\
\hline Cardiovascular diseases, $\mathrm{n}(\%)$ & $1,586(45.6)$ & $846(67.4)$ & $709(33.3)$ & $31(32.6)$ \\
\hline Taking antihypertensive treatment, $\mathrm{n}(\%)$ & $1,433(41.2)$ & $559(44.5)$ & $830(39.0)$ & $44(46.3)$ \\
\hline Age (years) & $48.0(38.0,59.0)$ & $47.0(38.0,58.0)$ & $49.0(38.0,59.0)$ & $51.0(45.0,62.0)$ \\
\hline Body mass index $(\mathrm{kg} / \mathrm{m} 2)$ & $22.8(20.8,24.9)$ & $22.5(20.7,24.9)$ & $22.9(20.8,25.0)$ & $22.4(20.1,24.6)$ \\
\hline Total cholesterol (mmol/L) & $4.5(3.7,5.2)$ & $4.4(3.6,5.2)$ & $4.5(3.7,5.2)$ & $4.6(4.2,5.2)$ \\
\hline Low density lipoprotein -cholesterol (mmol/L) & $2.6(2.0,3.2)$ & $2.5(2.0,3.2)$ & $2.6(2.1,3.2)$ & $2.6(2.1,3.0)$ \\
\hline High density lipoprotein -cholesterol (mmol/L) & $1.1(1.0,1.4)$ & $1.2(1.0,1.4)$ & $1.1(1.0,1.3)$ & $1.2(0.8,1.6)$ \\
\hline Triglyceride (mmol/L) & $1.2(1.0,1.8)$ & $1.2(0.9,1.6)$ & $1.3(1.0,1.9)$ & $1.1(0.8,1.2)$ \\
\hline Systolic blood pressure ( $\mathrm{mmHg}$ ) & $142.0(133.0,155.0)$ & $145.0(135.0,159.0)$ & $140.0(132.0,152.0)$ & $147.5(135.0,160.0)$ \\
\hline Diastolic blood pressure $(\mathrm{mmHg})$ & $86.0(80.0,94.0)$ & $87.0(80.0,93.0)$ & $85.0(80.0,94.0)$ & $90.0(80.0,100.0)$ \\
\hline Haemoglobin, g/L & $94.0(80.0,108.0)$ & $91.0(78.0,106.0)$ & $95.0(81.0,108.0)$ & $97.0(77.3,107.0)$ \\
\hline Reticulocyte, \% & $44.2(17.2,69.1)$ & $44.6(20.0,67.2)$ & $45.6(18.9,77.0)$ & $45.2(50.0,71.0)$ \\
\hline Phosphorus, mg/dl & $1.7(1.4,2.1)$ & $1.7(1.3,2.0)$ & $1.7(1.4,2.1)$ & $1.9(1.5,2.2)$ \\
\hline Albumin, g/L & $34.0(30.2,38.0)$ & $32.6(29.0,36.2)$ & $34.6(31.0,38.6)$ & $34.3(28.3,38.3)$ \\
\hline Total iron binding capacity , $\mu \mathrm{mol} / \mathrm{L}$ & $46.7(36.2,52.3)$ & $46.7(36.2,52.7)$ & $47.1(36.7,52.2)$ & $49.0(35.0,58.9)$ \\
\hline Creatinine, $\mu \mathrm{mol} / \mathrm{L}$ & $872.0(687.1,1093.0)$ & $884.8(685.0,1117.0)$ & $866.0(690.0,1069.9)$ & $824.0(620.0,916.1)$ \\
\hline estimated Glomerular Filtration rate, $\mathrm{mL} / \mathrm{min} / 1.73 \mathrm{~m}^{2}$ & $1.5(0.4,3.3)$ & $1.3(0.4,2.9)$ & $1.7(0.5,3.8)$ & $1.6(0.8,3.6)$ \\
\hline Transferrin, $\mathrm{mg} / \mathrm{dl}$ & $185.0(100.0,388.2)$ & $192.5(110.1,427.5)$ & $185.0(101.9,361.0)$ & $187.4(107.4,389.5)$ \\
\hline Total protein, $\mathrm{g} / \mathrm{L}$ & $58.0(52.7,62.8)$ & $56.6(51.4,60.8)$ & $58.6(54.0,63.8)$ & $53.3(47.2,62.2)$ \\
\hline Prealbumin, mg/L & $316.5(227.0,385.0)$ & $311.4(234.0,377.8)$ & $321.0(224.0,390.0)$ & $349.2(214.0,397.4)$ \\
\hline Fasting glucose, $\mathrm{mmol} / \mathrm{L}$ & $4.8(4.3,5.5)$ & $4.7(4.2,5.4)$ & $4.8(4.3,5.5)$ & $4.6(4.1,5.0)$ \\
\hline Sodium, $\mathrm{mEq} / \mathrm{L}$ & $140.0(137.0,143.0)$ & $139.8(137.0,142.3)$ & $140.0(137.6,143.0)$ & $140.0(136.0,143.0)$ \\
\hline C-reaction protein, $\mathrm{mg} / \mathrm{dl}$ & $2.2(0.9,5.0)$ & $2.3(0.9,6.1)$ & $2.1(1.0,4.5)$ & $1.12(1.01,1.22)$ \\
\hline
\end{tabular}

Fig. 1. Patterns of dialysate / plasma creatinine ratios in the peritoneal equilibration test. Grey square dash-dot line, Latent class $1(\mathrm{n}=1,255$, $36.1 \%$ ); grey diamond dash-dot line, Latent class 2 $(n=2,127,61.2 \%)$; black circle dash-dot line, Latent class 3 $(\mathrm{n}=95,2.7 \%)$. D0: dialysate creatinine at 0 hours; D2: dialysate creatinine at 2 hours; D4: dialysate creatinine at 4 hours; P: plasma creatinine at 0 hours.

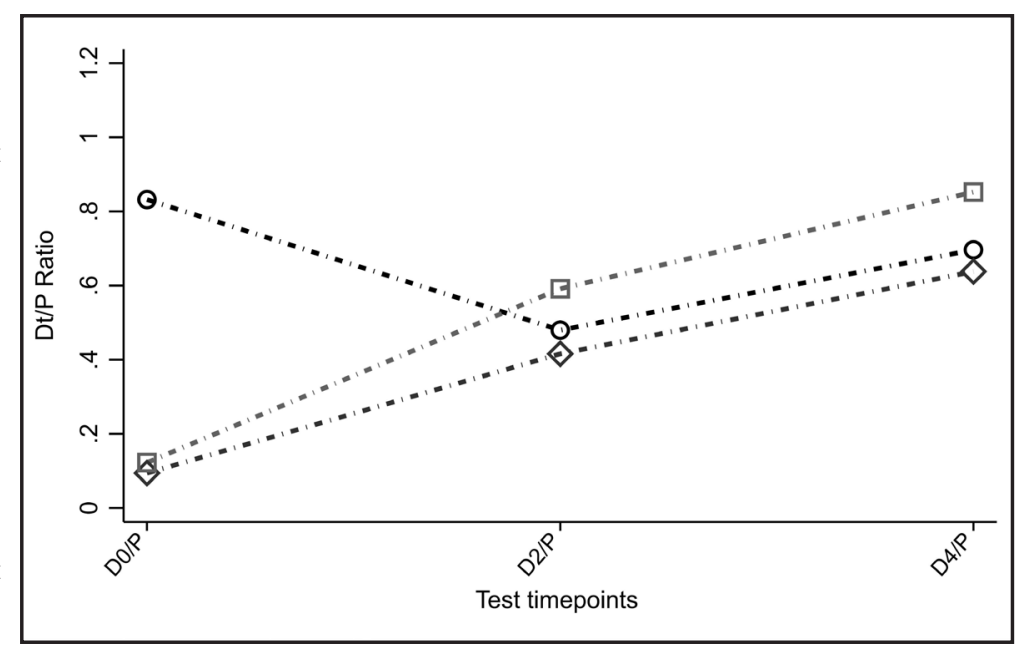

Class 1 and class 2 both demonstrated the lowest D0/P ratio $(0.123$ (95\% confidence interval (CI) 0.121, 0.124) for class 1 and $0.094(0.093,0.095)$ for class 2) and dramatic increase over the following 2 hours $(0.591(0.589,0.594)$ for class 1 and $0.416(0.414,0.417)$ for class 2$)$ and 4 hours $(0.852(0.850,0.855)$ for class 1 and $0.638(0.636,0.640)$ for class 2 ). Class 3 presented distinctively different trajectory from class 1 and 2, as higher ratio at 0 hour $(0.832(0.827,0.837))$ and dramatically decreased ratio at 2 hour $(0.480(0.475$, $0.484))$ and increased ratio at 4 hour $(0.696(0.692,0.701))$ (Fig. 1).

Characteristics of study participants stratified by latent classes are shown in Table 1. Class 1 , characterised by the lowest median age (47 years), the highest proportion of male gender $(63.3 \%)$, the highest prevalence of previous diagnosed cardiovascular diseases (67.4\%), the lowest median estimated glomerular filtration rate (eGFR) $\left(1.3 \mathrm{ml} / \mathrm{min} / 1.73 \mathrm{~m}^{2}\right)$, the lowest median prealbumin $(311.4 \mathrm{mg} / \mathrm{dl})$ and the highest median C-reaction protein (CRP) $(2.3 \mathrm{mg} / \mathrm{dl})$. 


\section{Kidney Blood Pressure Research}

Yu et al.: Dialysate Creatinine Response Patterns and Cardiovascular Mortality

Table 2. Crude incidence rates and adjusted odds ratios ( $95 \%$ confidence interval) for cardiovascular mortality by latent class. N, number of cardiovascular deaths. Model 1: adjusted for age, and gender. Model 2: adjusted for co-variables presented in Table 1

\begin{tabular}{lcccc}
\hline \multirow{2}{*}{ Class } & \multirow{2}{*}{$\mathrm{N}$} & Incidence rate $(95 \% \mathrm{CI}), \%$ & \multicolumn{2}{c}{ Odds Ratio $(95 \% \mathrm{CI})$} \\
& & & Model 1 & Model 2 \\
\hline Class 1 & 170 & $13.55(11.70,15.56)$ & Reference & Reference \\
Class 2 & 192 & $9.03(7.84,10.33)$ & $0.63(0.61,0.66)$ & $0.65(0.62,0.69)$ \\
Class 3 & 7 & $7.37(3.01,14.59)$ & $0.48(0.41,0.57)$ & $0.45(0.38,0.54)$ \\
\hline
\end{tabular}

Patients in Class 2 had the highest median body mass index $\left(22.9 \mathrm{~kg} / \mathrm{m}^{2}\right)$, the lowest median blood pressure measures (140 and $85 \mathrm{mmHg}$ for systolic blood pressure (SBP) and diastolic blood pressure (DBP)), the highest median haemoglobin $(95.0 \mathrm{~g} / \mathrm{L})$, the highest median total protein $(58.6 \mathrm{~g} / \mathrm{L})$, and the highest eGFR $\left(1.7 \mathrm{ml} / \mathrm{min} / 1.73 \mathrm{~m}^{2}\right)$.

Patients in Class 3 had the lowest proportion of male gender (53.5\%), the highest median age (51 years), the lowest prevalence of previously diagnosed cardiovascular diseases (32.6\%), the highest proportion of taking antihypertensive prescriptions (46.3\%), the highest median blood pressure measures (147.5 and $90.0 \mathrm{mmHg}$ for SBP and DBP), the highest median haemoglobin $(97.0 \mathrm{~g} / \mathrm{L})$, the highest median total iron binding capacity $(49.0 \mu \mathrm{mol} / \mathrm{L})$, the lowest median creatinine $(824.0 \mu \mathrm{mol} / \mathrm{L})$, the lowest median total protein $(53.3 \mathrm{~g} / \mathrm{L})$, the lowest median fasting glucose $(4.6 \mathrm{mmol} / \mathrm{L})$ and the median lowest CRP $(1.12$ $\mathrm{mg} / \mathrm{dl})$.

Absolute Numbers and mortality rates with adjusted odd ratios for 2-year cardiovascular mortality are provided in Table 2. The 2-year mortality rate was $13.611 .7,15.6) \%, 9.0$ (7.8, $10.3) \%$, and $7.4(3.0,14.6) \%$ for Class 1 , Class 2 , and Class 3, respectively. In the most adjusted model, patients in Class 2 has a 35\% decreased risk (Odds ratio (OR) 0.650 .62 , 0.69)) of cardiovascular death and 55\% decreased risk of patients in Class 3 (0.45 (95 CI: $0.38,0.54)$ ), with comparison to patients in Class 1.

\section{Discussion}

Applying a novel latent class trajectory analysis approach, this study revealed heterogeneity in dialysate creatinine response to PET test. We identified three different patterns and were able to associate them to the long-term outcome, cardiovascular mortality rate. Two groups (Class 3 and 2) characterised by decreased dialysate / plasma creatinine ratio between 0 - hour and 2-hour and/or low ratios at 2- and 4-hour over the PET were associated with low risks of cardiovascular mortality.

Class 3 and 2 were identified as more favourable response patterns, as patients belonging to Class 3 and Class 2 had 55\% and 35\% decreased risk of cardiovascular mortality comparing with those in Class 1 . Intermediate time points, especially D4/P, were also found to be superior marker for all-cause mortality and hospitalisation in another study [10]. Similarly, comparing with patients in Class 1, lower D4/P was characterised among patients in Class 3 and Class 2, which was associated with lower risk of cardiovascular mortality. This might be explained by the lower proportion of existing CVD in the classes, which has been reported in other studies $[16,17]$. This might also be due to the higher proportion of taking antihypertensive medicine in the class, which leading to the potential protection effect in the cardiovascular system [18]. We also observed the better remained kidney function in patients within Class 3 and 2 that could also play a role in the relative slow progress of CVD, as observed in previous study $[18,19]$. The systematic inflammatory status has been proved to contribute the premature death of CVD by previous studies [20]. In our study, the lower level CRP (the surrogate of the systematic inflammatory) was identified in patients within Class 3 and Class 2. The plasma glucose level also has been proved to be a significant dominant for cardiovascular mortality among PD patients [21]. In this study, the lower level 


\section{Kidney \\ Blood Pressure Research}

of glucose among patients within Class 3 and Class 2 might contribute to their lower risk of cardiovascular mortality. Risk factors generally reflecting the general health status, like haemoglobin and prealbumin were observed higher in Class 3 and 2, all of which could also contribute to the decreased risk of cardiovascular mortality as observed in other studies [22-24]. Moreover, lower blood pressure measurements in Class 2 comparing with Class 1 might also explain the lower cardiovascular mortality in Class 2.

In previous studies, one time-point $\mathrm{Dt} / \mathrm{P}$ ratio was used to predict the future risk of longterm outcome [10]. However, such measurements have limitations, as individual patients with different dialysate creatinine response trajectories can still have similar values for several calculate curve features. Therefore, instead of studying predefined curve characteristics, we considered heterogeneity of change using the data-driven approach. Latent class trajectory analysis allows the investigation of change over time, while taking measurement error into account. Compared with conventional approaches assessing only mean growth curves, the latent class method is suitable to reveal heterogeneous patterns, which may give us a more complete picture of associations.

It is notable to bear in mind that the aim of this study was not to derive the best prediction model or to determine optimal cut-off values for the examined outcomes, but to find associations that might not have been revealed with conventional methods. We observed that different dialysate creatinine response patterns during PET are associated with differed risks of cardiovascular mortality, which cannot be fully explained by differences in cardiometabolic risk profiles. This suggests that dialysate creatinine measurements at different time points should be considered simultaneously to get a more detailed picture of a patient's risk of future cardiovascular mortality. One limitation aspect that needs further investigation is the difference in cardiovascular mortality rates between classes, because the event numbers in the different classes were low and we did not have enough power to examine in details which exact cause contributed to the excess cardiovascular mortality rates in Class 3 compared with Class 1 . Moreover, our results might be influenced by confounding by unmeasured risk factors, for example, those due to under-recording of pre-existing comorbidities and their duration. The duration of reduced renal function would be a particularly important measure prone to under-estimation. Thirdly, we lacked data on lifestyle factors, including smoking, drinking and physical activity. Fourthly, we did not adjust for PD patients' socioeconomic status that would likely impact on PD patients' treatment/management status and their general health status. Finally, the proportion of clinical measurement data that was missing was relatively high requiring multiple imputation, which suggesting that further replication in the external dataset are warranted.

\section{Conclusion}

PD patients with decreased dialysate / plasma creatinine ratio between 0 - hour and 2-hour and low ratios at 2-and 4-hour are more likely to have low risk of future cardiovascular mortality. Latent class analysis seems to be a promising method to reveal unidentified subgroups that do not fit into the risk category defined by dialysate / plasma creatinine ratio at 4-hour.

\section{Disclosure Statement}

The authors declare that they have no competing interests. 


\section{Kidney Bloód Pressure Research} \begin{tabular}{l|l}
\hline Kidney Blood Press Res 2018;43:162-169 \\
\hline DOI: 10.1159/000487498 & $\begin{array}{l}\text { ( ) 2018 The Author(s). Published by S. Karger AG, Basel } \\
\text { www.karger.com/kbr }\end{array}$ \\
\hline Published online: February 21, 2018
\end{tabular}

\section{Acknowledgements}

We thank the First Affiliated hospital of Zhengzhou University approved this study. We thank Henan Peritoneal Dialysis Registry (HPDR) to provide the data for this study. This work was supported by The National Natural Science Foundation of China (Grant No. 81570690) and Science and Technology Innovation Team of Henan (Grant No. 17IRTSTHN020).

\section{References}

-1 Levin A, Tonelli M, Bonventre J, Coresh J, Donner JA, Fogo AB, Fox CS, Gansevoort RT, Heerspink HJL, Jardine M, Kasiske B, Kottgen A, Kretzler M, Levey AS, Luyckx VA, Mehta R, Moe O, Obrador G, Pannu N, Parikh CR, et al.: Global kidney health 2017 and beyond: a roadmap for closing gaps in care, research, and policy. Lancet 2017;390:1888-1917.

-2 Ojo A: Addressing the global burden of chronic kidney disease through clinical and translational research. Trans Am Clin Climatol Assoc 2014;125:229-243.

-3 Li PK, Chow KM, Van de Luijtgaarden MW, Johnson DW, Jager KJ, Mehrotra R, Naicker S, Pecoits-Filho $\mathrm{R}, \mathrm{Yu}$ XQ, Lameire N: Changes in the worldwide epidemiology of peritoneal dialysis. Nat Rev Nephrol 2017;13:90-103.

4 Yao Q, Duddington M: Peritoneal dialysis in China. Perit Dial Int 2014;34:S29-30.

-5 Vanholder R, Annemans L, Brown E, Gansevoort R, Gout-Zwart JJ, Lameire N, Morton RL, Oberbauer R, Postma MJ, Tonelli M, Biesen WV, Zoccali C, European Kidney Health Alliance: Reducing the costs of chronic kidney disease while delivering quality health care: a call to action. Nat Rev Nephrol 2017;13:393-409.

6 Wong FK, Li CS, Mak CK, Chau KF, Choi KS: Peritoneal equilibration test in Chinese patients. Adv Perit Dial 1994;10:38-41.

7 Mujais S, Nolph K, Gokal R, Blake P, Burkart J, Coles G, Kawaguchi Y, Kawanishi H, Korbet S, Krediet R, Lindholm B, Oreopoulos D, Rippe B, Selgas R: Evaluation and management of ultrafiltration problems in peritoneal dialysis. International Society for Peritoneal Dialysis Ad Hoc Committee on Ultrafiltration Management in Peritoneal Dialysis. Perit Dial Int 2000;20:S5-21.

-8 Akonur A, Guest S, Sloand JA, Leypoldt JK: Automated peritoneal dialysis prescriptions for enhancing sodium and fluid removal: a predictive analysis of optimized, patient-specific dwell times for the day period. Perit Dial Int 2013;33:646-654.

-9 Davies SJ: Mitigating peritoneal membrane characteristics in modern peritoneal dialysis therapy. Kidney Int Suppl 2006;70:S76-83.

10 Mehrotra R, Ravel V, Streja E, Kuttykrishnan S, Adams SV, Katz R, Molnar MZ, Kalantar-Zadeh K: Peritoneal Equilibration Test and Patient Outcomes. Clin J Am Soc Nephrol 2015;10:1990-2001.

-11 Berlin KS, Williams NA, Parra GR: An introduction to latent variable mixture modeling (part 1): overview and cross-sectional latent class and latent profile analyses. J Pediatr Psychol 2014;39:174-187.

12 Berlin KS, Parra GR, Williams NA: An introduction to latent variable mixture modeling (part 2): longitudinal latent class growth analysis and growth mixture models. J Pediatr Psychol 2014;39:188-203.

13 Green DJ, Jordan KP, Protheroe J, van der Windt DA: Development of hand phenotypes and changes in hand pain and problems over time in older people. Pain 2016;157:569-576.

14 Dunn KM, Campbell P, Jordan KP: Long-term trajectories of back pain: cohort study with 7-year follow-up. BMJ Open 2013;3:e003838.

15 Nicholls E, Thomas E, van der Windt DA, Croft PR, Peat G: Pain trajectory groups in persons with, or at high risk of, knee osteoarthritis: findings from the Knee Clinical Assessment Study and the Osteoarthritis Initiative. Osteoarthritis Cartilage 2014;22:2041-2050.

16 Ortega LM, Materson BJ: Hypertension in peritoneal dialysis patients: epidemiology, pathogenesis, and treatment. J Am Soc Hypertens 2011;5:128-136.

-17 Hoppe K, Schwermer K, Olewicz-Gawlik A, Klysz P, Kawka A, Baum E, Sikorska D, Scigacz K, Roszak M, Lindholm B, Pawlaczyk K, Oko A: Dialysis vintage and cardiovascular injury as factors influencing longterm survival in peritoneal dialysis and hemodialysis. Adv Clin Exp Med 2017;26:251-258. 


\section{Kidney \\ Blood Pressure Research}

Yu et al.: Dialysate Creatinine Response Patterns and Cardiovascular Mortality

18 Caravaca F, Alvarado R, Garcia-Pino G, Martinez-Gallardo R, Luna E: During the pre-dialysis stage of chronic kidney disease, which treatment is associated with better survival in dialysis? Nefrologia 2014;34:469-476.

19 Boyle SM, Li Y, Wilson FP, Glickman JD, Feldman HI: Association of Alternative Approaches to Normalizing Peritoneal Dialysis Clearance with Mortality and Technique Failure: A Retrospective Analysis Using the United States Renal Data System-Dialysis Morbidity and Mortality Study, Wave 2. Perit Dial Int 2017;37:8593.

-20 Liu YL, Liu JH, Wang IK, Ju SW, Yu TM, Chen IR, Liu YC, Huang CM, Lin SY, Chang CT, Huang CC: Association of inflammatory cytokines with mortality in peritoneal dialysis patients. Biomedicine (Taipei) 2017;7:1.

-21 Grantham CE, Hull KL, Graham-Brown MPM, March DS, Burton JO: The Potential Cardiovascular Benefits of Low-Glucose Degradation Product, Biocompatible Peritoneal Dialysis Fluids: A Review of the Literature. Perit Dial Int 2017;37:375-383.

22 Enia G, Panuccio V, Cutrupi S, Pizzini P, Tripepi G, Mallamaci F, Zoccali C: Subclinical hypothyroidism is linked to micro-inflammation and predicts death in continuous ambulatory peritoneal dialysis. Nephrol Dial Transplant 2007;22:538-544.

-23 Fein PA, Gundumalla G, Jorden A, Matza B, Chattopadhyay J, Avram MM: Usefulness of bioelectrical impedance analysis in monitoring nutrition status and survival of peritoneal dialysis patients. Adv Perit Dial 2002;18:195-199.

-24 Krishnamoorthy V, Sunder S, Mahapatra HS, Verma H, Sharma N, Jayaraman R, Sathi S, Khanna S, Mohamed A: Evaluation of Protein-Energy Wasting and Inflammation on Patients Undergoing Continuous Ambulatory Peritoneal Dialysis and its Correlations. Nephrourol Mon 2015;7:e33143. 